\title{
Signifikansi Kajian Bahasa Semit dalam Linguistik Arab
}

\author{
Abdul Muta’ali \\ Program Studi Arab, Fakultas Ilmu Pengetahuan Budaya, \\ Universitas Indonesia, Depok, Jawa Barat 16424 \\ E-mail: moeta_aly@yahoo.com
}

Abstrak - Bahasa Semit adalah cabang bahasa Afro-Asiatik yang paling besar, selain merupakan yang terluas dalam rumpun bahasa ini bahasa semit juga bahasa yang paling awal yang sampai secara tulisan kepada kita. Tidak ada kesepakatan yang pasti diantara para ahli bahasa dan ahli sejarah tentang tempat dimana bahasa Afro-Asiatik bermula. Ada yang mengatakan bahasa ini bermula dari Ethiopia, ada juga yang mengatakan bermula dari daerah Levant, bahkan ada juga yang mengatakan berasal dari Kenya. Para penutur cabang bahasa ini seringkali menganggap bahwa mereka adalah anak keturunan Sem, salah seorang putra Nabi Nuh, karena itulah nama cabang ini disebut sebagai bahasa Semit. Di antara bahasa-bahasa Semit sendiri, bahasa mereka ini mempunyai warna yang unik. yang secara pengucapan dan ejaan disebut sebagai Tri-Literal atau menggunakan konsonan sebagai dasar arti. Bahasa semit memiliki empat cabang bahasa yang terbagi dalam akkadi, kan'an, aromi dan janibi. Studi tentang bahasa Semit ini akan mengantarkan kita kepada studi yang lebih komprehensif rumpun-rumpun bahasa ini, salah satunya adalah bahasa Arab.

Abstract - The Semith language is the most AfroAsiatic language and the larges language area came us have writing and the faster. Discourse about it until now, no there are one opinion between linguistics scholars and histories scholars where the first place of semit growing. Many scholars says that Ethiopia and Levant its the first place. The others Scholars says it's Kenya. Speakers of this tongue has claim that they are is the Sam family, he is one of a prophet Nuh's son. So, it was inspired to give this brand of language as Semit Language. In its self, there are many colours and uniqies; like verbalition and aplhabetic, so Tri-Literal called. Or use consonan as basic meaning. The Semit language have four language parts, there are Accady, Can'an, Aromy, and Janiby. The study of this tongue bring us to more comprehenshif studies about the various of this family language, one of them is Arabic language.

Keywords - Semith, Accady, Can'an, Aromy, Janiby

\section{PENDAHULUAN}

$\mathrm{R}$ umpun bahasa Afro-Asia secara genealogi rumpun bahasa di dunia, merupakan rumpun bahasa terluas. Mencakup beberapa macam bahasa: Semit, Mesir Kuno, Barbar, Kushitik dan Tashadi. Rumpun menempati peringkat ke-6 dalam jumlah banyaknya bahasa dalam satu rumpun, yakni berjumlah 374 bahasa. Bahasa Afro-Asiatik yang terbesar adalah bahasa Arab yang menempati urutan ke-5 dalam banyaknya penutur asli, sejumlah 221 juta lebih penutur asli. ${ }^{2}$ Saat ini, istilah 'Bangsa-bangsa Semit' (Samiyyin) ditujukan untuk bangsa Aramaic (Aramiyyah), Phoenicia (Finiqiya), Hebrew ('Ibriyya), BabylonianAssyrian (Babiloniyya-Asyuriyya), bangsa Arab, dan Yaman. Artinya, bahasa-bahasa Semit adalah bahasa yang terbentang di negara-negara Asia dan Afrika. Bahasa Semit merupakan bahasa tertua di dunia yang termodifikasi.

\footnotetext{
${ }^{1}$ Muhammad Fahmi Hijazi, Mudkhal ila Ilmi lughiah, (ad-Dar al-Misriah as-Saudiah), 2006. hal.207

2 Dalam rumpun bahasa Afro-Asiatik sendiri, terdapat sejumlah bahasa yang dikenal sebagai bahasa yang dipakai sebagai bahasa Klasik keagamaan, antara lain, dan bahasa Ibrani (Hebrew) yang dipakai sebagai bahasa klasik agama Yahudi dan Kristen, dimana kedua bahasa tersebut sama-sama merupakan cabang dari bahasa Semit. Walaupun demikian, rumpun bahasa Afro-Asiatik didominasi oleh bahasa Arab sebagai bahasa klasik dan modern paling utama.
} 
Schlozer dan Eichorn, ${ }^{3}$ merupakan orang pertama yang menggunakan istilah Semit pada permulaan akhir abad kedelapan belas, tepatnya pada tahun $1781 \mathrm{M}^{4}$ Pada abad IV, 7 abad sebelum Schlozer, Ibnu Hazm dalam Al-Ihkam fi Ushul Al-Ahkam telah menjelaskan adanya korelasi yang sangat kuat antara bahasa Arab dengan bahasa-bahasa Semit yang lain. Dalam karyanya tersebut Ibnu Hazm mengatakan "kita sangat yakin bahwa bahasa Suryani, Ibrani, dan bahasa Arab, yang merupakan bahasa kabilah Mudhar adalah satu bahasa. Perubahan terjadi karena proses urbanisasi, perbedaan negeri, dan pengaruh budaya lain. Barang siapa yang mencermati ketiga bahasa tersebut secara seksama, ia akan sangat yakin bahwa bahasa-bahasa tersebut pada mulanya adalah satu bahasa. ${ }^{5}$ Penamaan itu sendiri berangkat dan terpengaruh dari salah satu bab dalam Taurat tentang bagan silsilah tiga orang putra Nuh, diantaranya "Sam, Ham, dan Yaputs" dan keturunan yang lahir dari ketiganya. Hasil penelitian itu menyebutkan, bahwa keturunan yang berasal dari Sam diantaranya, 'Ilam, Asyur, Arfiksyad, Lud, dan Aram. Selanjutnya lahirlah dari keturunan Arfiksyad; Syilasy, Syilasy Abir sebagai bapak dari keturunan Hebrew ('Ibriyya). ${ }^{6}$

Pembagian dan penjelasan tentang keturunan Nuh menurut penelitian di atas, nampaknya lebih didasarkan kepada hubungan politik, budaya, dan geografis, bukan berdasarkan hubungan kekerabatan dan kewargaan. Sehingga, Lydiens (Lidiyyin) dan Elymeen ('Ilamiyyin) dianggap sebagai bangsa Semit, hanya karena alasan afiliasi dan kepatuhan politik mereka kepada kalangan Assyrian. Padahal, mereka adalah pihak asing bagi bangsa Semit. ${ }^{7}$ Bahasa-bahasa yang termasuk dalam keluarga bahasa Semit diantaranya, bahasa Akadiyah (Babylonian-Assyrian), Aramiyyah, Kan'aniyyah (Phoenicia dan Ibriyya), bahasa Arab, Yaman klasik, dan Habasyah (Abyssinia). ${ }^{8}$ Mahmud Ukasyah dalam 'Ilm Lughah membagi bahasa Semit secara umum pada dua kelompok; Semit Timur dan Semit Barat. Semit Barat terbagi kepada Semit Barat Laut dan Semit Barat Daya.

\footnotetext{
3 Keduanya adalah ahli bahasa berkebangsaan Jerman.

4 A. Walfinsen, Tarikh Lughat al-Samiyyah, hal. 9.

5 Ibnu Hazm, Al-Ihkam fi Ushul Al-Ahkam, hal 49.

6 Lihat bab Safar al-Takwin (Penelitian tentang pembentukan komunitas dalam Kitab Kejadian).

7 Ramadhan Abd Tawwab, Fushul fi Fiqh al'Arabiyyah, hal. 26. lihat juga Ali Abdul Wahid Wafi, Fiqh Lughah, hal.6-7.

8 Ali Abdul Wahid Wafi, Ilm Lughah, hal. 201.
}

Semit Barat Laut terdiri dari dua bahasa, yaitu bahasa Kan'an dan bahasa Aramiyyah. ${ }^{9}$ Sedangkan yang termasuk ke dalam bahasa Semit Timur adalah bahasa Akadiyyah dengan dua cabang bahasanya; yaitu Babiliyyah dan Asyuriyyah.

\section{KERANGKA TEORI / TINJAUAN PUSTAKA}

Penulis menggunakan dua teori untuk menganalisa terkait kajian semit ini. Pertama teori Ali Abdul Wahid Wafi yang tertuang pada karya besarnya, Fiqh Lughah. Karya inilah yang dikemudian hari menjadi 'buku wajib' pada sarjana yang concern pada kajian linguistik dan philology Arab. Teori kedua penulis menggunakan teori Ramadhan Abd Thawwab yang tertuang pada Fushul fi Figh Lughah al-Arabiyyah.

Menurut Ali Abdul Wahid Wafi, bahasa-bahasa Semit yang beraneka ragam berasal dari one of lanzirah language species (fashilah wahidah). Dengan demikian, menurut Wafi tidak diragukan lagi komunitas atau bangsa-bangsa semit yang tersebar di belahan dunia berasal pula dari satu tempat atau negeri. ${ }^{10}$ Para ahli bahasa dan sejarawan sejalan dengan Wafi. Namun, di negeri mana yang pertama lahirnya komunitas Semit? Hal ini yang menjadi kontroversi. Ramadhan Abduttawwab dalam Fushul fi Fiqh al-Arabiyyah mengatakan ada empat mazhab mengenai komunitas Semit berasal; Mazhab Afrika (yang mengatakan bahwa komunitas Semit berasal dari benua Afrika), Mazhab Armenia (yang mengatakan bahwa komunitas Semit berasal dari negeri perbatasan Armenia dan Kurdistan), Mazhab Babilonia (yang mengatakan bahwa komunitas Semit berasal dari negeri Furat), dan Mazhab Arab (yang mengatakan bahwa komunitas Semit berasal dari jazirah Arab). ${ }^{11}$

Jika dirangkum dari beberapa pendapat, paling tidak terdapat enam pendapat mengenai negeri tempat lahirnya komunitas Semit.

1) Pendapat pertama, mengatakan bahwa komunitas Semit berawal dari negeri Habasyah. Kemudian komunitas ini migrasi ke selatan

9 Mahmud Ukasyah, 'Ilm Lughah; Madkhal Nazhariy fi al-Lughah al-Arabiyyah, hal. 242.

${ }^{10}$ Ali Abdul Wahid Wafi, Fiqh Lughah, hal. 8-9.

11 Ramadhan Abduttawwab, Fushul fi Fiqh alArabiyyah, Maktabah Khanji, Kairo, 1999, cet. 6, hal. $38-42$. 
Arab melalui jalan pintu Mandab. Dari Mandab inilah mereka menyebar ke seantero Jazirah Arab.

2) Pendapat kedua, berpendapat bahwa mereka berasal dari Afrika utara. Dari situ, menyebar ke Asia melalui terusan Suez.

3) Pendapat ketiga, mengatakan asal bangsa Semit dari negeri Armenia dekat dengan Kurdistan. ${ }^{12}$

4) Menurut Guidi, komunitas Semit berasal dari negeri Selatan Iraq. Pendapat ini didasarkan dengan adanya beberapa kosakata serapan antara keduanya yang berkaitan dengan kehidupan, hewan, dan tumbuh-tumbuhan.

5) Sebagian para ahli sejarah mengatakan bahwa negeri Kan'an merupakan daerah asli komunitas Semit. Argumen ini didasari karena masyarakat Semit banyak tersebar di negeri Suria dahulu kala dan tidak diketahui peradaban lain sebelum peradaban negeri ini.

6) Para orientalis termasuk Renan -seorang ahli bahasa berkebangsaan Prancis- dan Brockelmann -linguis berkebangsaan Jermancenderung berpendapat bahwa komunitas Semit berawal dari Barat daya negeri-negeri Arab, seperti Hijaz, Nejd, dan Yaman.

Ali Abdul Wahid Wafi mengatakan bahwa pendapat Renan dan Brockelmann ini mendekati kebenaran dan lebih relevan dengan peninggalanpeninggalan dan dokumentasi sejarah. ${ }^{13}$ Karena negeri-negeri Hijaz, Nejd, dan Yaman adalah tempat tujuan pertama Migrasi pada zaman prasejarah dan masa-masa sejarah sampai ke utara dan timur Suria, Iraq, dan sekitarnya. ${ }^{14}$ Bukan hanya Wafi, Caetani de Teano pun menguatkan pendapat Renan dan Brockelmann. Menurut Teano negerinegeri tersebut pada masa pra-sejarah adalah negeri yang padat penduduknya, subur tanahnya, melimpah ruah hasil buminya, dan dilalui oleh tiga sungai besar. Masa-masa selanjutnya, musim kemarau melanda negeri ini dan sungai-sungai pun kering. Akhirnya, komunitas Semit pun hijrah ke negeri lain yang lebih bisa menjamin keberlangsungan hidup mereka. Argumen Teano ini didukung beberapa penelitian Geologi terhadap negeri ini. Jika kita amati seluruh pendapat dan argument di atas, nampak bahwa migrasi pertama

12 Ketiga pendapat tersebut sangat lemah. Karena tidak memiliki argumen yang jelas.

${ }^{13}$ Ali Abdul Wahid Wafi, Fiqh Lughah, hal. 10.

${ }^{14}$ Untuk lebih luasnya baca Ali Abdul Wahid Wafi, Fiqh Lughah, hal. 10. bangsa Semit ke Habsyah dimulai dari negeri Yaman. ${ }^{15}$

\section{METODE PENELITIAN}

Kajian tentang tema ini menggunakan pendekatan studi kepustakaan dengan metode penelitian kualitatif. Data-data diperoleh dari literatur-literatur linguistik, philologi, dan sejarah. Karena itu, penelitian tentang kajian ini juga sedikit banyak menggunakan tipe historical method.

Terdapat dua kajian penelitian mengenai bahasabahasa Semit. Pertama, mengenai penelitian umum berkenaan dengan sejarah, pertumbuhan, dan perkembangannya. Kedua, kajian khusus mengenai fonologi, kaidah kebahasaan, struktur kalimat, dan kosakatanya. Ahli bahasa yang paling populer meneliti tentang sejarah, pertumbuhan, dan perkembangan bahasa Semit diantaranya seorang linguis Perancis, Renan dengan karyanya Histoire Generale et systeme compare des langues semetiques yang ditulis pada pertengahan abad ke $19 \mathrm{M}$ dan seorang linguis berkebangsaan Jerman, Noldeke. Sedangkan ahli bahasa yang concern dalam penelitian fonologi, kaidah kebahasaan, struktur kalimat, dan kosakata bahasa Semit diantaranya Wright dengan bukunya Lectures on the Comparative Grammer of The Semitic Languages (1890), Zimmern dalam Vergleichende Grammatik der semitischen Sprachen (1898). Adapun yang meneliti dua kajian itu sekaligus adalah Brokelmann dalam beberapa karyanya,

15 Tidak ada kesepakatan diantara para ahli bahasa dan ahli sejarah tentang tempat dimana bahasa AfroAsiatik bermula. ada yang mengatakan bahasa ini bermula dari Ethiopia, ada juga yang mengatakan bermula dari daerah Levant, bahan ada juga yang mengatakan berasal dari Kenya. Bahasa Semit mempunyai warna yang unik. yang secara pengucapan dan ejaan disebut sebagai Tri-Literal/menggunakan konsonan sebagai dasar arti. Bahasa semit memiliki empat cabang bahasa yang terbagi dalam akkadi, kan'an, aromi dan janibi. Dalam referensi lain, bahasa Semit (secara umum) terbagi menjadi dua bagian yaitu: Syarqiah (Timur) dan Ghorbiah (Barat). Semit Barat terbagi lagi menjadi Barat Utara dan Barat Selatan. Adapun Semit Timur mencakup Akadiah dengan cabang Babilonia dan Asyuriah, yang sampai pada kita dengan beberapa tulisan, menggunakan tulisan Musmar. Sedang Semit Utara terbagi menjadi dua bahasa, yaitu bahasa Kan'an dan bahasa Aromiah. Bahasa Kan'an terbagi lagi Kan'an Utara dan Kan'an Selatan. 
seperti Grundrissder vergleichen den Grammatik der Semitischen Sprachen (1908), Kurzgefasste vergleichende Grammatik (1908), dan Semitisch Sprachwissenschaft (1906).

\section{IV.HASIL DAN PEMBAHASAN}

\subsection{Bahasa Semit Pertama}

Bukan hanya mengenai negeri pertama mana komunitas Semit berasal, para sejarawan dan pakar bahasa pun berselisih pendapat mengenai bahasa pertama yang digunakan oleh komunitas Semit. Sebagian peneliti mengatakan bahwa para pendeta Yahudi pada masa klasik mempunyai keyakinan bahasa Ibrani adalah bahasa manusia yang tertua. Para ahli sejarah juga ada yang mengatakan bahwa bahasa Semit yang pertama adalah bahasa Babylonian-Assyrian. Beberapa sejarawan dan ahli bahasa modern seperti Olshausen berpendapat bahwa bahasa Arab adalah bahasa yang paling mirip dengan bahasa Semit yang pertama.

Ketiga pendapat di atas tidak memiliki argumen yang kuat. Hal tersebut karena seluruh bahasa Semit telah mengalami beberapa fase perkembangan. Masing-masing bahasa tersebut semakin lama semakin jauh dari titik awal perkembangan induk bahasa Semit. Ada juga sebagian ahli bahasa yang berpendapat dengan meneliti persamaan-persamaan kosakata dan grammer antara bahasa Semit yang ada dalam menentukan bahasa Semit pertama. Pendapat inipun tidak beralasan. Pasalnya, persamaanpersamaan kebahasaan yang ada antara bahasabahasa Semit tidaklah menggambarkan mayoritas persamaan yang ada. Karena bahasa Semit telah melalui beberapa fase perkembangan. Yang sudah barang tentu persamaan tersebut tidak bisa disimpulkan sebagai bentuk bahasa Semit pertama. Namun, sebagian para orientalis berasumsi bahwa bahasa Arab merupakan satu-satunya bahasa yang paling banyak terjaga kosakata dan kaidah-kaidah bahasa Semit klasiknya. Hal ini disebabkan karena bahasa Arab tumbuh dan berkembang di negeri pertama komunitas Semit berada. Bahkan, Muhammad Ahmad Muzhar berpendapat bahwa bahasa Arab adalah induk bahasa manusia di dunia. $^{16}$

${ }^{16}$ Muhammad Ahmad Muzhar, Majalah Diyanat, India, vol. Februari-Oktober 1960 and vol. NovemberDesember 1960.
Menurut hemat penulis, bahwa para linguis Arab klasik bukan tidak tahu atau tidak memberikan perhatian khusus kepada bahasa Semit. Bahkan mereka dalam beberapa literature ditemukan sangat tahu akan adanya korelasi antara bahasa Arab dengan bahasa-bahasa Semit ini.

Hal tersebut dapat dilihat pada beberapa hasil temuan riset, diantaranya:

1) Khalil bin Ahmad Al-Farahidi (w. $175 \mathrm{H}$ ) dalam Al-'Ain mengatakan, "Kan'an bin Sam bin Nuh, sebagai nenek moyang bangsa Kan'an dan mereka berbicara dengan bahasa yang tidak jauh berbeda dengan bahasa Arab." 17

2) Abu Ubaid Qasim bin Salam seperti yang dikutip oleh Ramadhan Abd. Tawwab mengatakan adanya korelasi yang kuat antara bahasa Arab dengan bahasa Suryani. Dalam pernyataannya Abu Ubaid Qasim bin Salam menyimpulkan, "bahasa Arab memiliki beberapa ciri yang tidak dimiliki oleh bahasa bangsa lain di dunia seperti yang kami ketahui, diantaranya: adanya Alif dan Lam (ال) di awal kata benda seperti (الطور) yang dalam aturan I'rab bisa dalam kedudukan rafa' (baca: singular and broken plural (' $u$ '), double form (aa-n) (alif+nun), male plural (uu-n)), nashab (baca: singular and broken plural ('a'), double form (ai-n) (alif+ya), male plural (ii-n)), khafdh (baca: singular and broken plural (' $i$ '), double form (ai-n) (alif+ya), male plural (ii-n)). Dalam bahasa Suryani adaka kata mirip dengan kata Arab tersebut yaitu (طور) tanpa menggunakan Alif dan Lam di awal kata dan menambahkan alif di akhirnya. Dalam bahasa Suryani, Thuura ini dalam posisi I'rab bagaimana pun, baik rafa', nashb, dan khafdh hanya dibaca satu bentuk saja yaitu Thuura. Sedangkan dalam bahasa Arab, 'At-Thuur' bisa dibaca At-Thuuru dengan dhammah, At-Thuura dengan fathah, dan At-Thuuri dengan kasrah. Sama halnya dengan kata (اليمّ) dalam bahasa Arab dan (يمّا) dalam bahasa Suryani. Dalam bahasa Arab bisa dibaca Al-yammu, Al-yamma, dan Alyammi. Sedangkan dalam bahasa Suryani dalam posisi apapun harus dibaca Yamma. ${ }^{18}$

\footnotetext{
${ }^{17}$ Khalil bin Ahmad al-Farahidi, Al- 'Ain (Beirut: Dar Fikr, t.thn), juz 1, hal. 232.

${ }^{18}$ Ramadhan Abduttawwab, Ibid, hal. 43.
} 


\subsection{Karakteristik Bahasa Semit}

Terdapat beberapa karakteristik umum (khasha'ish musytarakah) yang sama dalam bahasa-bahasa Semit, baik dalam karakteristik bunyi, morfosintaksis, ataupun arti (dilalah). Karakteristik umum yang nampak pada seluruh rumpun bahasa Semit tersebut membuktikan bahwa dahulu bahasabahasa Semit adalah satu, atau yang biasa disebut dengan bahasa Arab klasik. ${ }^{19}$

\subsection{Karakteristik Bunyi}

Karakteristik bunyi ini diantaranya:

1) Dalam bahasa-bahasa Semit terdapat beberapa kelompok bunyi halq (pharyngal), seperti Hamzah, Ha, 'Ain, ha, ghin, dan kha. Menurut Mahmud Ukasyah, bahasa Arab mampu menjaga kelestarian bunyi-bunyi halq (pharyngal) tersebut. ${ }^{20}$

2) Bunyi huruf konsonan mempunyai peran penting dibanding bunyi layyin dalam tiga hal; makna, pengucapan, dan penulisan. ${ }^{21}$

3) Bahasa Semit memiliki bunyi muthbaqah seperti Shad, Dlod, Tha, dan Zha. Huruf-huruf ini masih terjaga dalam bahasa Arab.

4) Secara umum kata dasar dalam bahasa Semit terdiri dari tiga huruf konsonan yang berbeda $(q a-t a-l a), \quad(d l o-w a-b a), \quad\left(r a-j a-{ }^{\prime} a\right)$, dan lain sebagainya.

5) Hampir tidak ditemukan kata atau kosakata dalam bahasa Semit berasal lebih dari satu akar suku kata. Hal ini berbeda dengan bahasa India dan Eropa. Setiap kata pada jenis bahasa ini menunjukkan arti majemuk sesuai arti dasar yang terkandung dari suku kata tersebut.

6) Sebagian besar dalam bahasa Semit hanya memiliki dua kata kerja atau vearb, yaitu fi'l madli (kata kerja lampau) dan fi'l mudhari' (kata kerja sekarang).

7) Untuk men-ta'nits-kan noun (kata benda) atau adjective (kata sifat) dengan memberikan akhiran $t a$ ' pada kata tersebut.

\subsection{Karakteristik Sintaksis}

1) Bentuk kalimat pada bahasa-bahasa Semit terbagi menjadi mudzakkar (maskulin) dan mu'annats (feminin).

\footnotetext{
19 Mahmud Fahmi Hijazi, 'Ilm Lughah al-Arabiyyah, hal. 139-150.

${ }^{20}$ Mahmud Ukasyah, 'Ilm Lughah, hal. 286.

${ }^{21}$ Ali Abdul Wahid Wafi, Fiqh Lughah, hal. 79.
}

2) Dilihat dari segi nominal, bentuk kalimat dalam bahasa-bahasa Semit terbagi menjadi mufrad (singular), mutsanna (double form), dan Jamak (plural).

3) Bahasa Semit memiliki tiga perubahan posisi pada kata benda (ism); marfu', manshub, dan majrur.

\subsection{Karakteristik Semantik}

1) Nominal dasar terhitung dari dua sampai sepuluh.

2) Preposisi jarr diantaranya: min, fi, dan, 'ala.

3) Bahasa Semit memiliki banyak kosakata, khususnya kosakata tentang anatomi tubuh, kata ganti (pronoun), dan hubungan kekerabatan.

\section{KESIMPULAN}

Studi tentang bahasa Semit sangat penting karena kajian tentang bahasa ini baik itu peradabannya, agamanya, adat dan kebudayaan akan menjadi bahan perbandingan khususnya bagi para pemerhati, peneliti, dan pakar bahasa Arab. Mengingat penelitian pada satu bahasa bukan berarti hanya terfokus pada bahasa itu, tanpa melakukan kajian komparatif. Dalam hal ini, para peneliti Barat ketika meneliti dan mengkaji bahasa Arab, banyak temuan yang baru yang mereka dapatkan. Karena mereka meneliti bahasa Arab bukan dalam frame bahasa Arab, melainkan dalam kerangka Semit Studies. Coba perhatikan firman Allah SWT:

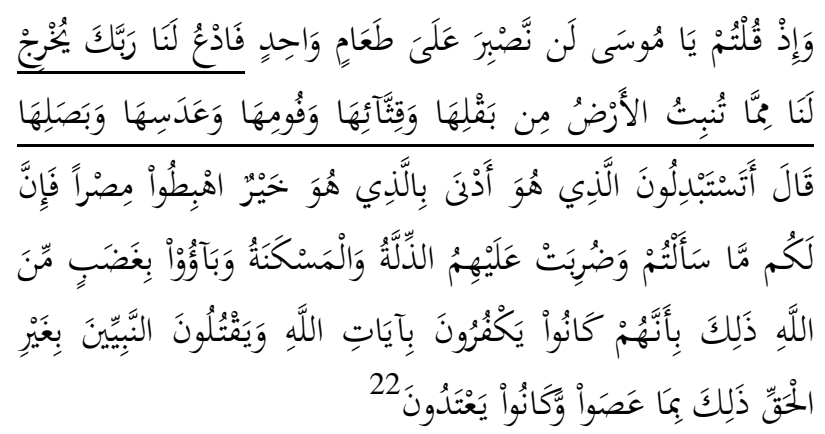

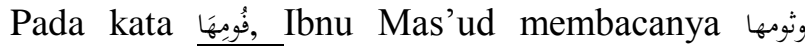
menggunakan Tsa (ث), berdasarkan riwayat dari Ibnu Abbas. Pertanyaannya, kata tersebut dalam bahasa Arab apakah aslinya menggunakan $T s a$ ' atau $\mathrm{Fa}^{\prime}$ ? Dalam kajian bahasa Semit, Syin (ش)

${ }^{22}$ Al-Baqarah: ayat 61. 
dalam bahasa Ibrani yang sepadan dengan $\mathrm{Ta}^{\prime}$ dalam bahasa Aramaic, padanan bunyinya dalam bahasa Arab adalah Tsa'. Contoh kata Syuur (شور) dalam bahasa Ibrani, sepadan dengan Tawra (تورا) dalam bahasa Aramaic dan Tsaur (ثر) dalam bahasa Arab. Begitu juga kata Syum (شوم) Ibrani, sama dengan Tawma (توما Aramaic dan Tsum (ثوم) dalam bahasa Arab.

Dengan demikian kata asli وَفْوِهَ adalah menggunakan $T s a^{\prime}$ sedangkan $\mathrm{Fa}^{\prime}$ adalah perkembangan bunyi dari $T_{s} a^{\prime}$. Bukan hanya kata

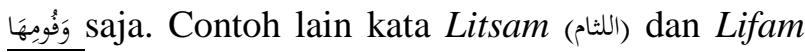
(الفأم), alfa'ru (الفأر) dan al-tsa'ru (الثأر). Menurut Ramadhan Abd. Tawwab, ${ }^{23}$ jika kaidah tersebut kita aplikasikan ke dalam kata kerja misalnya, Tsaaba (ثاب) artinya kembali. Dalam bahasa Arab terdapat kata yang searti dengan Tsaaba yaitu Taaba (تاب) artinya kembali dari dosa yang merupakan kata serapan dari bahasa Aramaic yang diambil dari teks-teks keagamaan. Juga kata Syaaba (شاب) Ibrani dan Taaba (تاب), searti dengan Tsaaba (ثاب) .

\section{DAFTAR ACUAN / PUSTAKA}

[1] Abd Tawwab, Ramadhan. Fushul fi Fiqh al'Arabiyyah (Kairo: Maktabah Khanji, 1999)

[2] Fahmi Hijazi, Muhammad. Mudkhal ila Ilmi lughiah, (Riyadh: Dar Misriah Saudiah, 2006)

[3] Hazm, Ibnu. Al-Ihkam fi Ushul Al-Ahkam (Beirut: Dar Fikr Arabiy, 2000)

[4] Muzhar, Muhammad Ahmad. Majalah Diyanat, India, vol. Februari-Oktober 1960 and vol. November-Desember 1960

[5] Ukasyah, Mahmud. 'Ilm Lughah; Madkhal Nazhariy fi al-Lughah al-Arabiyyah (Kairo: Alam Kutub, 2001)

[6] Wafi, Ali Abdul Wahid. Fiqh Lughah (Kairo: Dar Kutub El-Mishriyyah, 1995)

[7] Wafi, Ali Abdul Wahid. Ilm Lughah (Kairo: Dar Kutub El-Mishriyyah, 1994)

[8] Walfinsen, A. Tarikh Lughat al-Samiyyah (Kairo: Dar Angola El-Mishriyyah, 2004

${ }^{23}$ Contoh-contoh ini bisa dilihat dalam Ramadhan Abd Tawwab, Fushul fi Fiqh al- 'Arabiyyah, hal. 37-38. 